\title{
IMPACT OF IT GROWTH ON LABOUR DEMAND IN THE EU TRANSPORT INFRASTRUCTURE DEVELOPMENT
}

\author{
Andrius MONTRIMAS ${ }^{1} \mathbb{D}$, Vaidas GAIDELYS ${ }^{2 *}$ \\ ${ }^{I}$ AMENTER LTD, 145 A Plaistow Road, E15 3ET, London, United Kingdom \\ ${ }^{2}$ Department of Economics and International Trade, School of Economics and Business, \\ Kaunas University of Technology, K. Donelaičio St. 73, 44249 Kaunas, Lithuania \\ ${ }^{*}$ E-mail: Vaidas.Gaidelys@ktu.edu
}

\begin{abstract}
Purpose - the purpose of this research is to find the benchmark, triggering a significant shift of the EU transport infrastructure construction sector from usual labour to the IT-based project implementation. The work aims to find obstacles that hold off IT from booming in this sector.

Research methodology - following the literature overview, three bills of quantities of sample transport infrastructure construction projects selected as the objects for analysis and the mathematical-statistical method was applied to actually completed projects to find the benchmark for costs of respective IT development.
\end{abstract}

Findings - the findings of this work suggest a $10 \%$ benchmark of project scope, applicable for IT innovations at the expense of human labour demand.

Research limitations - EU financial support and public procurements of investment projects are mostly applicable for investment phase. This research is therefore limited to the analysis of investment activities.

Practical implications - the industry stakeholders would welcome the IT if innovations developed with the budget not exceeding the benchmark. IT researchers and developers could use the results for cost adjustments of their offered solutions to the EU transport construction companies.

Originality/Value - this work encourages discussions on initiation of the initiatives at the political level aiming to the requalification of the existing unemployed labour force in order to meet the current labour demand in the construction market as a whole. It provides a direction for future scientific researches and IT developers in order to increase the attractiveness of IT for application in construction projects.

Keywords: IT growth, labour demand, transport infrastructure, EU infrastructure, construction trends, IT innovations impact on labour.

JEL Classification: G11, L74, M54, O52.

Conference topic: Contemporary Financial Management.

\section{Introduction}

The European Union (EU) has committed to invest over EUR115 billion into the transport sector through various instruments during the 2014-2020 financial period. A same or higher level of investment should be committed by the EU for the next 2021-2027 programming period. The need for investment into the Trans-European Transport (TEN-T) Core Network Corridors alone by 2030 is around EUR 750 billion (European Commission, 2019). EU in this context is not the main investment contributor as it offers a partial contribution. The EU member states are the main ones. Funding is the main tool for the EU to develop a single transport area throughout all EU member states. The constructed single transport network would later serve as the basis for the long-term economic development in the area. The topic of smooth and uninterrupted growth of the EU's transport sector, therefore, deserves special attention from various levels of the EU institutions and the legislative bodies of the EU member states.

The EU, of course, is not the only economy to be largely investing in the development of its transport networks. China's Belt and Road (or the Silk Road of the 21 -st Century) initiative is advancing through as many as 60 countries around the world. It aims to develop infrastructure corridors for the latter smooth intermodal transportation of Chinese goods all over the world. Estimated investment costs are up to $\$ 8$ trillion (The Hong Kong Trade Development Council, 2019). 
Analysis of the reasoning behind these substantial amounts of investments committed would most likely show a picture that humanity has completed its an expansion on the earth's territories and the world economy is naturally slowing down. If expansion to other planets is not an option yet, then what's next? One of the most promising solutions, in this case, would be to facilitate the infrastructure, sufficient enough for all needs of smooth trade in the world. And this is exactly what the most powerful economies in the world are doing now.

Another large investment priority nowadays in the world is the IT sector development. Current break-through of IT innovations has provided a tremendous variety of possibilities to transform businesses. Investment amounts of the world's leading economies into IT development are quite significant as well. The State Council of the People's Republic of China has issued a guideline with a total investment of $\$ 147.8$ billion to become a global innovator in the field of Artificial Intelligence (AI) by 2030 (State Council of the People's Republic of China, 2017). In 2016 the United States (US) has spent approximately $\$ 1.2$ billion on research and development of AI-related technologies to promote AI researchers and AI education programs (Holdren and Smith, 2016). Europe has spent up to $€ 700$ million on robotics and public-private partnerships that develop AI technologies (Ansip, 2017). Zhu, Song, Ni, Ren, and Li (2016) argue that the path to new business models has never been wider than now. They are confident that digital technologies transform the business world. According to them, in the digital age, change is the only thing that is permanent. There are no arguments against this position, however...

A practical look to the previously mentioned EU's transport infrastructure construction sector shows no significant shift from manual labour powered construction operations to IT-based operations. In spite of large amounts of EU's funding, dedicated to the technology research and innovation, the old-fashioned construction labour (usual labour) is still essential in this sector and, therefore it is still growing. What are the main reasons for this phenomenon? Why progressive IT novelties, proven efficient (and more effective than usual labour) in other economic sectors, are still in the outskirts of interest of the industry stakeholders? Why the growth of IT does not have a significant impact on labour in this sector so far? Lastly, what has to happen for the situation to change?

It is known that any innovation requires long hours of engineering, development and more and more programming labour. These hours of labour turn into the development costs the developers want to get the reimbursement for. The more sophisticated the innovations, the more engineering, developing and programming they require. Hence, innovations become costly for construction companies to purchase.

The decision-makers of the construction companies, on the other hand, when in search for optimisation, do not look at the price tags only. It is understandable that the investment costs of innovations reimburse in the long run with more efficient operations. There are other important factors that (apart from investment costs) the decision-makers of relying on when they decide whether to invest in IT-based operations or to remain in the old setup. The designed automated tools are based on pure blue-sky research without consideration on economic aspect will usually go belly up (Yi \& Li, 2018).

Addressing these questions this research evaluates the obstacles that hold off IT innovations from practically blending into the construction operations of transport infrastructure construction sector. It also aims to find out how much extent it is available for the applicability of IT innovations in this sector and under what conditions would businesses be willing to shift to IT-based operations, thus essentially reducing the demand of old-fashioned construction labour.

Success to complete the strategic transportation system development goals, raised by the EU, largely depends on the measures taken to achieve these goals. Measures to meet the demand for the development of transport infrastructure in the EU are usually defined in the format of investment projects by amount, specificity and other criteria of transport infrastructure subsystems. Every investment project, implemented by a public authority or a state-owned company, has to undergo public procurement procedures for selection of the most effective delivery. When it comes to competition of construction companies for the most effective delivery in the context of public procurement, cost optimisation becomes the target for every contestant. Scope and technical complexity of investment projects, especially in transport infrastructure construction sector, has been significantly increasing together with the increase of the amounts of funding allocated for them. On the other hand, the ever-increasing complexity of various legal and environmental requirements along the public procurement procedures, together with the harsh competition of suppliers has made it harder to pass through the required procedures in the pre-investment stage. The projects tend to be postponed, cancelled or delayed. The competition consequently increases even more. A new age of intense competition is just beginning, one in which the winner takes all (Zhu, Song, Ni, Ren, \& Li, 2016). Suppliers understand that they have to change, to optimise if they want to stay in the market.

A theory of basic economics suggests that every change in a business model requires some level of sacrifice. By applying a change in a production line in continuous operations a business risks to suffer some level of losses before it starts to accumulate gains. Just like a medical surgery. One way or another, a surgeon has to cut the body open to apply a vital change inside the living organism. It would later have a positive impact on the patient's health. Prior to that though, the patient's body will have to put some effort to heal the wound and it is never a pleasant experience.

How should the management of an old-fashioned and well-run transport infrastructure construction business behave? In the environment, when the production volume is high, current operational capacity is not even close to the limit, completion of several large construction contracts in progress and at the same time, the company is about to win 
a large construction tender. New IT technologies, which could boost the business in the long run, are there in the market. But they have many unknowns that might hurt current operations; clients' trust and might cause other costrelated problems. Competitors most likely are upgrading to the new digital operational setup, but they are not winning the tenders so far. They are becoming more competitive than before though. When is the best time to take the action and begin transformation? Or maybe it's better to wait and see what innovations the IT market will provide several years later?

The above-described problem is a complex one in all levels of decision-making. According to H. L. Mencken, for every complex problem, there is an answer that is clear, simple, and wrong.

Aiming to avoid a simple and wrong answer to this complex problem, this research applies a detailed analysis of bills of quantities of three different sample transport infrastructure construction projects (transport projects) by applying average proportions of high-skilled and low-skilled labour, mechanisms and materials within the components of bills of quantities, evaluated in the winning bids of actually completed EU's transport projects. A bill of quantities is chosen as the object of this research due to the fact that it is an object of cost optimisation for construction businesses when participating in transport projects as well. Finding an extent for potential substitution of usual labour with a novelty IT solution for the acceptable price could be the reason for a construction business decision-maker to decide to shift to IT-based operations. It is, therefore, reasonable to test the hypothesis, stating that there is a significant extent in the scope of a transport infrastructure construction project for cost optimisation with IT innovations.

The first task of the research is to analyse the applicability of IT innovations, available on the market. The second task is to identify the general obstacles, holding off these IT innovations from being applied to the works within the bills of quantities. The third task aims to identify the works, foreseen in the bills of quantities of selected sample transport projects, which could be optimised by applying IT innovations. Lastly, the fourth task is to calculate the cost level in each of the bills of quantities by summing up costs of the foreseen works, identified in the third task. The result gives an indication of the budget limitations (the benchmark), recommended for the developers of IT innovations that are looking to sell their technologies to the transport infrastructure industry stakeholders.

The logic of a construction business decision-maker states that a construction company would be willing to shift from usual labour-based operations to the IT-based if convinced that the IT innovations will complete all the same tasks that are currently completed by usual labour, but with less effort and within the same or lesser budget than the usual labour requires. If (and whenever) the IT developers are capable to stay within the benchmark with their development costs, the IT-based solutions will become attractive to construction businesses. Consequently, IT innovations on a large-scale, developed within the benchmark in the context of transport projects, would result in the transport infrastructure construction sector in the EU to witness a large-scale impact of IT growth on labour. A significant shift from man-powered construction labour to IT-based operations would become attractive to the industry.

The purpose of this analysis, therefore, is to find the benchmark, triggering the significant shift of the EU transport infrastructure construction sector from usual labour to the IT-based infrastructure project implementation, which would cause a significant impact of IT growth to the labour demand.

\section{Literature review}

Many publications, devoted to the introduction of new IT technologies, provide a wide variety of solutions that are ready to be applied. There is a wide range of activities in the construction industry that are suitable for introduction of innovations, such as design solutions, technological, technical and economic solutions, decision-making methods, organizational solutions, efficient management and more. Various dimensions of BIM, augmented reality, robotics and exoskeletons, Internet of Things (IoT), drones, cloud computing, AI, Smart Buildings and similar novelty technologies are viewed by scholars as the solutions that should be largely influencing the world's construction industry within one or two years (Kaplinski, 2018). All of them are based on the application of big data analytics and information management.

A number of scholars analyse these technologies in detail, providing their application possibilities. A short overview of innovations suggested to be best suitable for the construction industry is provided below.

Zhu, Song, Ni, Ren, and Li (2016) provide examples of capabilities the big data analytics tools, applied to construction projects, replace a significant number of project implementation personnel and reduce project costs by eliminating paperwork and significantly reducing possibilities of human errors. Three important aspects for further analysis are underlined. The first one is the value of big data that comes from the ability of IT solutions to instantly analyse it. The second one - big data solutions must be tailored to each industry. This work has to be performed by skilled analysts and administrators who know both the industry and all aspects of technology. The experts are hard to find today and the demand for such workers is increasing drastically. The third important aspect is that big data solutions are very much involved in the process of bringing the cost of many goods and services towards zero if the openness of data is ensured. Hence, the construction companies, when facing a decision to shift to the big data tools, have to make a choice whether to stay with limited capabilities and higher risks of human errors of existing employees, or to substitute existing employees with the big data analytics tools and to hire expensive, skilled big data experts, who would tailor the big data tools to the company's operations and later maintain them for proper operation. 
Dimitriou, Marinelli, and Fragkakis (2018) analyse accurate cost estimation solutions for preliminary stages of project development. Accurately estimated the cost of a large and complex project significantly increases chances to win the tenders. Based on big data principle, the introduced solutions analyse various sets of information from previously completed projects and provide accurate estimation for the bill of quantities. It allows for avoiding cost overruns during the project implementation phase. It is explained that 9 out of 10 transport infrastructure projects fall victim to cost escalation, which for fixed links (tunnels and bridges) and roads has an average value of $34 \%$ and $20 \%$ respectively. It should be noted that these solutions are effective for construction companies when having a sufficient amount of data from previous projects, entered into the database. Human resources are required for entering and updating the information in the database, so these technologies could even increase the human labour demand in the short term.

Demian and Walters (2014) explore BIM, a multi-dimensional modelling technology, one of the main contributors to the optimization of problem-solving, especially in the construction business. BIM is presented as a construction design tool that can reduce errors between $50 \%$ and $90 \%$ and thus to significantly lower the construction costs. The BIM tools are costly though, and therefore unattractive for many companies from the first glance. The popularity of BIM solutions, however, nowadays is growing as they are among the trending IT innovations in the construction sector (Kaplinski, 2018).

Shehab (2009) presents the radio-frequency identification (RFID) system as the solution for tracking construction assets, laser scanning, web-based applications and the basis for other sensing technologies. With respect to that, practice shows that many competitive contractors of the transport sector in the EU have applied the RFID technology on their machinery not only for tracking but also for construction precision, which eliminates the necessity of repetitive works. This technology in the context of transport project implementation is quite promising.

Additive manufacturing (three-dimensional, or 3D printing), suggested by YI and Li (2018), is another IT-based technology, widely compatible with BIM, and has significant potential to become one of the main tools for construction companies. It has huge potential to become irreplaceable in modular construction, as it is capable of replacing human labour with fully automated operations when constructing various structures on site. Berman (2012) presents a successful application of $3 \mathrm{D}$ printing in a bridge construction project when the tools were costly, complex and time-consuming. Anyhow, Perkins and Skitmore (2015a) suggest that the current 3D printing is unsuited to large-scale products and traditional design approaches, as it has a very limited range of materials, which can be used.

Special attention by a number of scholars is given to the development of robotics solutions. For current workers on the construction sites, there is now wearable robotics. $\mathrm{Li}$ and $\mathrm{Ng}$ (2017) analyse capabilities of this robot suit technology that lessens the user's back stress by 15 kilograms. These solutions increase productivity reduces costs of construction companies, but they still need the same amount of human labour for operations.

Many advantages together with even more issues arise with the wake of AI-driven robots. Being able to instantly analyse big data and gathering commands from BIM related solutions, robots are viewed as future substitutes of low-skilled employees as well as some skilled functions (Wladawsky-Berger, 2017).

$\mathrm{Yi}$ and $\mathrm{Li}$ (2018) reveal that the use of robots for autonomous construction of the superstructure of buildings, thus optimizing efforts and substituting workers to perform heavy work, underwater constructions, performing hazardous and complicated works. Acemoglu and Restrepo (2017) estimate that one more robot per thousand workers lowers the employment to population ratio by about $0.18-0.34 \%$ and wages by $0.25-0.5 \%$, whereas Raviv, Shapira, and Barak (2017b) suggest that well-designed robots can increase productivity on construction sites by eliminating human error-caused accidents, which account to $80-90 \%$ of all on-site accidents.

A topic of application of machine learning in construction project implementation has been active for almost 40 years already. An expert system introduced and in-detail described by Fenves (1984) provides grounds for discussion on machine learning - an essential feature of contemporary robotics. IT has sparked many discussions about the future of human-tomachine interaction and cooperation. The theory assumes that a construction project could be fully implemented by machinery by using machine learning techniques. This approach would require close to none human labour, independently of the project scope. Industry stakeholders, as well as researchers, are hesitant with the development and application of machine learning in various fields due to public safety issues, which are not solved yet. Boddington (2017) raises an issue that the more powerful AI becomes, the less control over the AI's actions humans will have. He, therefore, opens a discussion on how AI will deal with values of humanity, which is a central concern to ethics. This comes in line with the decision-making of customers and suppliers in transport infrastructure construction sector, as a lack of control of AI's actions might not guarantee the safety of the structures, later used by humans. Stamper's (1988) introduced theory of de-contextualization appeared quite obvious in sectors that are more advanced in applying AI to usual operations the than the construction sector. A perfect example, in this case, comes from experience with AI solutions in medicine. Karches (2018) explains AI's own rationalized representation of human beings. Such behaviour is usually not designed for the better of human beings, but rather for an optimal economic effect, whereas the decision making of a human assessor or supervisor is oriented towards the safety of future use of the construction subsystems. This issue is a crucial one in the context of future opportunities for AI to take over the implementation of safety assessment procedures in transport infrastructure construction sector.

The above-described innovative solutions are currently becoming attractive to construction companies in the United States and the trends should reach Europe with certain latency (Kaplinski, 2018). Once applied in the construction sector, the trending solutions will have an impact on the industry and, especially on the labour market. Probst, Monfardini, Frideres, and 
Cedola (2014), pay attention to the EU's reported socio-economic relevance, including demographical change, environmental factor and better quality of life. Publications of Jones (2018) and Kaplinski (2018) however conclude that these trends would cause (among other effects) labour force shortages.

The issue of labour shortages is outlined in the context of the Fourth Industrial Revolution, currently progressing EU. Kohnová, Papula and Salajova (2019) note the decreased demand for employees performing routine activities and significantly increased demand for digital staffing, which will require highly skilled personnel to manage digitalised processes.

Ciborowski (2016) furthermore elaborates on the effect of labour demand changes, caused by the introduction of IT innovations. He notes that cheap labour due to a factor of major influence on the location of business has declined as a source of comparative advantages. It, therefore, has caused advanced technologies to become a substitute for cheap labour offered by developing countries. In fact, this change has created huge disadvantages for small local businesses all over Europe since small construction companies are incapable to find relatively large amounts of investments required for adaptation of novelty technologies. This change, moreover, opened more opportunities for large corporations as they have available investment resources to apply novelty IT solutions.

Smart specialisation and knowledge-intensive development are perceived as the predominant direction of changes that should be occurring in the EU's societies, enabling continuous growth of innovativeness (Roszko-Wójtowicz \& Białek, 2019). After studying the impact of sectoral unemployment in the Mediterranean countries - the ones with the biggest unemployment rates in the EU, Dimian, Aceleanu, Ileanu, and Serban (2018) have concluded that bad specialisation could explain the existence of those high unemployment rates in industrial sectors. Their findings point toward the educational mismatches, not meeting the trending demands, caused by the growth of IT-based employment demand.

The underperformance of human labour is another major disadvantage in the construction business. Trade Unions and policy-makers have put a great deal of effort to protect the jobs of low-skilled workers. Merriman (2017) provides calculations showing that low-skilled employee replacement costs are more than 3 times higher than average monthly compensation, occurring at the companies in the US. This rate differs in the EU from country to country. But one way or another, it is a burden for businesses. Furthermore, Alsop's (2008) findings on predominant anxiousness of mindset of the current major workforce generation - the millennials - complete a strange picture of the current situation of the labour market in the construction sector. On one hand, the market appears to be growing as the demand (and funding) for construction increases. On the other hand, there is a huge demand for low-skilled work in the transport infrastructure construction sector in the EU. Interestingly enough, the low-skilled overall unemployment is booming due to educational mismatches and (most likely) due to the worker's mindset issues of the current generation. Relatively high costs, many unknowns and unwillingness to risk with safety, as stipulated by Dziadosz, Tomczyk, and Kaplinski (2015), leads to quite often rejections of the applications of IT innovations in the EU's construction sector when the IT innovations are booming and creating shortages of high-skilled data management-related employment.

In this difficult environment, a notion of complementarity between humans and IT technologies needs to be assessed, because it can solve partial employment demand issues in order to meet the foreseen goals. Jarrahi (2018) presents and describes a possible effective complementarity between humans when applying IT novelties to analytical work and other similar activities, involving large amounts of data, while the activities of safety assessment and non-standard decision making are implemented by humans.

Summary of the reviewed literature suggests major opportunities for integration of various IT innovations into the construction and development activities in general. When it comes to the decision-making, however, there are practical obstacles preventing industry stakeholders to shift to IT-based operations for project implementation. In the environment of high-skilled labour shortages for operations of IT-based technologies as well as low-skilled labour shortages due to educational mismatches and behavioural issues, businesses are quite sceptical to proceed with IT-oriented transformations in their operational processes.

The reviewed literature, apart from various benefits of IT innovations, linked to the operational efficiency of construction works, suggests the main obstacles, holding off the IT innovations to be applied in construction projects, are the following:

1. Financial considerations - costs include IT development expenses, costly software and hardware engineers for tailored applications, service during operations and maintenance.

2. Many unknown factors in the practical operations of IT-based technology.

3. Questionable safety of results, completed by using IT innovations. Insurance does not cover construction liability and product liability, completed by an unproven and untested technology. There is a lack of sufficient legislation in most EU countries to cover this issue.

4. Social uncertainty threatens society due to the risk that IT innovations might take away humans' workplaces.

Having in mind the above-listed obstacles and striving to find the best use out of the advantages of IT innovations, it is suggested to consider quite significant construction project optimisation opportunities when applying IT technologies to analytical work and other similar activities, involving large amounts of data. The limitations of performance of IT novelties, however, should be limited to the boundaries of safety-related decision making. 


\section{Methodology}

The literature overview has provided answers to the first two tasks of the research. The results showed the areas within a transport project scope, most suitable for IT innovations that are available on the market, including their limitations (due to revealed obstacles) in order to achieve their complementarity man-powered labour for optimal project implementation.

The right project cost estimation is the key to successful bidding in a transport project tender. Prior to submission of a tender proposal, the bill of quantities is broken down piece by piece by the bidder's analysts in order to find possibilities to optimise the bid, yet still to have a marginal profit.

The problem is that all other competitors, who are in pursuit of the same contract, are doing the same. So, if all bidders know the project scope quite well, their estimations on project costs are very similar. But the winning bid will be the lowest price. Hence, if you want to win the bid you either have to minimise your expected profit and hope that you will not have any cost overruns during the project implementation, or you have to apply more effective project implementation technologies, which could give you some room for fluctuations. The good thing, in this case, is that the larger the project scope, the more complex it is and the more possibilities for fluctuations are there. The bad thing is that the larger the scope, the bigger the risk of cost overruns, which could even lead the company to bankruptcy.

Further analysis applies the mathematical-statistical method to the iterated bills of quantities from the previously completed tenders of 10 complex transport projects. The selected projects have been implemented by construction companies from 7 countries in the time frame between 2010 and 2018. It is important to note that the bills of quantities of these transport projects were based on the usual labour.

The bills of quantities were iterated to the level of components (separate works by nature). Then, the components were compared among each other throughout all completed transport projects of this analysis, thus showing several important aspects:

- Each project has a different set of components, depending on the complexity and the nature of the project. However, the works by their nature, defined in the separate components, are similar throughout most of the projects. For example, a road construction project often includes a bit of reconstruction of a railway crossing, or an urban infrastructure construction project often deals with an adaptation of roads and railway-related infrastructure, etc.

- Cost of works, defined in each component, is the sum of labour costs, equipment costs and materials. The proportion of costs for labour, equipment and materials differs depending on the nature of work. Interestingly enough, these proportions remain similar throughout time. It shows that in general labour costs, equipment costs and costs for materials increase at a similar pace throughout time. The same works by nature in different projects, however, have similar proportions between labour, equipment and material costs. They differ from project to project by the amount. This means that, for example, embankment construction works will include a different amount of works in a road project and in a rail project, but the proportions of labour, equipment and materials, required to complete the embankment construction work in both projects will be similar.

- Each work by its nature includes some amount of high-skilled labour due to the fact that the EU's transport infrastructure constructions are highly formalised by various safety and interoperability procedures. Moreover, the works that include low-skilled employment have a share of inspection and supervision tasks, devoted to high-skilled labour. Inspection and site supervision tasks within a construction project scope are separate from the tasks of technical supervision because each completed work has to be evaluated, documented and prepared for proper reception by technical supervision. High-skilled engineers on site usually organise the documentation and preparation for inspections as well as they are responsible for the proper performance of low-skilled workers.

Next, the average proportions of high skilled and low-skilled labour, equipment and materials of each component, observed in the aforementioned analysis, are applied to the three sample transport projects. In order to avoid confidentiality issues, the sample projects are taken from the publically available case studies, presented by the European Commission (2014) in the EU's main working document for calculation of the cost-benefit analysis of the EU investment projects: (1) Road project, (2) Railway project, (3) Urban transport project are further referred to as the Sample projects. The scope and the investment breakdown of the Sample projects provided in the reference (European Commission, 2014) as follows:

1. Road project - pages 101 and 103 respectively;

2. Railway project - pages 114 and 116 respectively;

3. Urban transport project - pages 127 and 131 respectively.

The source of reference clarifies that the investment costs of the Sample projects are based on the tender prices for awarded construction works and rolling stock purchases. Consequently, the analysis applies the average proportions of the actual completed projects to the costs of the respective components with the following relationship:

$$
C_{\mathrm{Spc}}=100 \%=S_{\mathrm{AhslP}}+S_{\mathrm{AlslP}}+S_{\mathrm{AeP}}+S_{\mathrm{AmP}},
$$


where:

$C_{\mathrm{Spc}}-\operatorname{cost}$ (or budget) of a component, represented in a bill of quantities of a Sample project;

$S_{\text {AhslP }}$ - share (or proportion) of high-skilled employment in the total cost of the component. Supervision and safety

assessment labour, as well as other analytical and management-related work included;

$S_{\text {AlsIP }}$ - share (or proportion) of low-skilled employment in the total cost of the component;

$S_{\text {AeP }}$ - share (or proportion)of equipment in the total cost of the component. Machinery and tools, used for the works to be completed, included in the component;

$S_{\mathrm{AmP}}$ - share (or proportion) of cthe ost of the materials installed in the total cost of the component. Preassembled in factories parts of structures and factory-assembled rolling stock included in the component.

\section{Object analysis}

Having the previously described database, the next step is to evaluate the applicability of the integration of IT innovations into the iterated components of the Sample projects. The aggregated overview is presented below:

Administrative tasks include land purchase, construction permission acquisition, publicity measures and technical assistance activities.

Land purchase or construction permission acquisition procedures require flexible interaction with government institutions for various architectural decisions (or sometimes initiation of changes in legislation) and reached agreements with the landowners that are usually not too happy to give up their land to a state-promoted project.

Technical assistance and project supervision activities are fully depended on human performance because these are safety-critical procedures that ensure proper construction assessment throughout the project.

Publicity measures usually derive from the customer's requirements. The cost of this task is nearly invisible in the bill of quantities, so the executives of large construction companies, when preparing for a project tender, do not pay much attention to it. In spite of the fact that there are affordable IT tools that can completely take over the implementation of publicity measures, in most cases construction companies ignore it. Publicity measures of a project, such as articles in the newspaper or online, posts in social networks and sometimes organisation of TV reports, are quite rare and standard. However, the logic of a company manager prefers to employ one decent worker who can deal with all publicity issues without any request for additional support and additionally to deal with other tasks rather than to buy a program that requires an additional person, which has to burn many hours figuring out how to operate it and then to supervise it.

The information above suggests that all the components that represent the administrative tasks have practically no extent for adaptation of IT innovations in the current construction environment.

Research activities are the basis for the project quality. They include pre-design site survey and inspection works. Usually, two or three environmental engineers perform geology and geodesy surveys whereas design engineers record the current status of the construction site. They perform various measures, take samples and record their findings to the project database. Later this information is delivered for designing. Geology, geodesy and other site inspections prior to the construction are not costly. In the Sample Road, Railway and Urban transport project bills of quantities they account for $0.2 \%, 0.4 \%$ and $0,4 \%$ respectively. They are extremely time-consuming though. For example, one team of three analysts can perform geodesy analysis of up to 400 meters of a railway line in a rural territory per working day. Such a slow pace, therefore, becomes the reason for construction companies to search for IT technology solutions.

Big data-driven IT tools, such as drones and various other scanning machines, today are capable to perform rough geodesy and territorial inspection works 10-20 times faster. The quality of information gathered in such way, of course, cannot be reliable by itself. In this case, the assistance of big data analytics by adjusting the findings according to all the information gathered from other overlapping surveys effectively solves the problem.

Automation of landscape and construction site inspection procedures significantly reduces demand for human work. Instead of a team of three environmental engineers, it is enough to have one engineer with a drone. Previously planned six teams of three can now transfer into six engineers with six drones. Additional engineer for accumulation and processing of centrally gathered information might be needed too. Nevertheless, a site inspection will be performed many times faster than before. With this notion an extent for optimisation of the bills of quantities by substituting human labour and old equipment with IT-based innovations in the Sample projects becomes real.

Design activities are on the brink of transformation to fully digitalized BIM technology-based tasks. Built upon the concepts of three-dimensional modelling by incorporating non-graphical object data into the model, BIM generally refers to a modelling technology with a set of processes to produce, analyse and communicate building models. (Yi \& Li, 2018) BIM has evolved to be able to process up to six-dimensions at once. According to Vysotskiy, Makarov, Zolotova, and Tuchkevich (2015), the global trend in using BIM technology involves three-dimensional design and life cycle analysis. Survey analysis, completed by using automated solutions, quickly transferred to BIM software, where the designers can draw their visions of new constructions. This IT-based setup is bound to significantly alter the bills of quantities of the Sample projects by reducing the amount of human labour and previously used design software. 
Construction phase activities consume the vast majority of costs. The bills of quantities foresee $84.7 \%, 88.1 \%$ and $81.7 \%$ of total costs in the Road, Railway and Urban transport Sample projects respectively. Earthworks, road construction, railway track construction, tram infrastructure construction, construction of structures (tunnels, bridges, retaining walls, noise barriers, etc.) are the works that require a lot of pre-produced or raw materials. The analysis of the Projects has shown a very similar distribution of labour, equipment and material shares in the context of the components of the bills of quantities.

Construction companies usually calculate that roughly $60 \%-80 \%$ of the costs of the related components should be distributed to purchase of materials. Another significant share of the costs of these tasks goes to the transportation of the materials. Sand, ballast, asphalt, wooden and steel materials or casts, rails, sleepers, pre-produced concrete blocks and other materials are delivered to the construction sites using different transportation technologies, starting from heavy haul trucks to sea transport to even custom-made railway rolling stock for transportation of oversized materials. This reveals that in case of integration of IT novelties in project scope, the costs of materials and their transportation would remain the same.

There are usually two groups of workforce performing the basic construction phase activities. The first group consists of skilled and usually experienced workers: on-site managers, engineers, plant machinery operators, safety inspectors and similar. These well-paid employees are usually in charge of smooth and safe operations. The EU, national laws and the customers require work inspection and supervision activities by quality personnel for every task and subtask of a project. High-skilled technology engineers, as well as machinery operators (in the Railway project case, who are skilled enough to manage IT-based operations), are included in this group as well. The contemporary IT sector boom drastically increased the demand for highly skilled engineers in all sectors. So, for a company to consider replacing it's decently performing high skilled engineers and managers with IT technologies could be suicidal.

The second group consists of low-skilled construction workers. They have some engineering background and they have completed basic safety instructions. Their usual work is related to the performance of simple and repetitive tasks. The work is mostly physical and requires a limited amount of mind work.

Application of IT by deployment a robot on a construction site appears to be quite tempting opportunity for construction companies that deal with underperformance and various legislative issues that eliminate flexibility of employment management, described in the literature review section. Such an opportunity for a construction company to optimise operations costs and increase productivity can put the business among the next winners of large tenders. Therefore a significant extent appears as the substitute for low-skilled employment for IT innovations in these construction phase components.

Intelligent transport systems are signalling, traffic information and management systems. Equipment and materials (including delivery) combine for about $75 \%$ since the essential part of equipment are pre-assembled IT-based solutions, purchased from a technology supplier, such as Siemens, Bombardier, Alstom, Thales and other. The equipment is installed and adjusted by high-skilled engineers, quite often dealing with the safety critical installations and programming. Optimisation of these is currently ongoing towards the development of more automated, big data and cloud computing based equipment, which requires less and less wayside equipment. The novelty systems require more programming though. Construction companies during project implementation are usually obligated to organise the delivery of preassembled equipment to the construction site and organise custom installations of the equipment by high-skilled programmers. Hence, it leaves no significant extent for construction companies to optimise.

Railway construction machines that work on the sites of construction projects deserve a separate task in the bill of quantities of the Sample Railway project. Track laying machines, tamping machines for works on railway sites, heavy haul cranes, strong enough to be able to lift concrete pre-produced constructions for bridges and viaducts, tunnel digging and other similar machinery is usually quite unique, adapted for certain works in certain regions and hence the limited number of operating units are usually hard to find available. Most of the times several major projects, implemented in parallel, have to adapt their work plans due to needing to share the same plant machinery, because of it's limited availability in a region of several countries. Such machinery, consequently, requires special personnel to operate it. Limited supply and custom skills make these operators exceptional therefore the costs of such operations. In order to operate this kind of machinery, an operator has to be not only skilled in driving an oversized machine on site but also has to fully understand and manage the IT tools installed in the machine.

The urban transport Sample project has a separate task, related to rolling stock too. This task foresees the manufacturing of trams. Construction companies during project implementation purchase the completed rolling stock units from the factories. The integration of the IT innovations, in the context of this research, therefore, has no significant impact on the rolling stock production and delivery activities as well.

Based on the evaluation of possibilities for integration of the IT innovations into separate fields of works within the Sample projects, the targeted parts of the components, subject for replacement (fully or partially) with the IT technologies, are shown below (Table 1).

Rough estimations based on the information of the literature review are presenting the following affect the IT integration into the components, listed in Table 1:

Automation of the site inspection activities (geology, geodesy, etc.) transforms the distribution of costs to around $10 \%$ share of the tasks provided for environmental engineers with additional competence to operate the IT innovations. The site inspection equipment, used in usual labour setup, would not be necessary to use anymore if IT novelties, applicable for these tasks were integrated, because the automated equipment has all the necessary site inspection features together with many more. 
The design activities, after the integration of BIM and other related data management solutions, still require a significant contribution from human engineers in the process of creation. Moreover, design activities include pre and post construction assessment activities. Consequently, a rough estimation of $52 \%$ of the total costs of design activities is proposed to remain for distribution to the high-skilled workforce.

Table 1. List of components of the Sample projects with possibilities to integrate IT innovations. The targeted parts of components, subject for replacement with IT innovations, presented in bold

\begin{tabular}{|c|c|c|c|c|}
\hline $\begin{array}{c}\text { Components } \\
\left(\boldsymbol{C}_{\mathrm{Spc}}\right)\end{array}$ & $\begin{array}{c}\text { High-skilled labour } \\
\text { Avg.share of cost, \% }\end{array}$ & $\begin{array}{c}\text { Low-skilled labour } \\
\text { Avg.share of cost, \% }\end{array}$ & $\begin{array}{c}\text { Equipment } \\
\text { Avg.share of cost, \% }\end{array}$ & $\begin{array}{c}\text { Materials } \\
\text { Avg.share of cost, \% }\end{array}$ \\
\hline Geodesy & $\mathbf{7 9}$ & - & 21 & - \\
\hline Geology & $\mathbf{7 7}$ & - & 23 & - \\
\hline Design & $\mathbf{7 8}$ & - & 22 & 64 \\
\hline Earthworks & 2 & $\mathbf{1 5}$ & 19 & 62 \\
\hline Road/Rail & 2 & $\mathbf{1 5}$ & 21 & 73 \\
\hline Structures & 2 & $\mathbf{1 3}$ & 12 & 64 \\
\hline Buildings & 3 & $\mathbf{1 4}$ & 19 & 81 \\
\hline Noise and safety barriers & 1 & $\mathbf{8}$ & 10 & - \\
\hline
\end{tabular}

Optimisation of construction phase activities by replacing low-skilled workforce with robotics solutions is quite feasible. It, however, would require additional high-skilled workforce for supervision of the behaviour and maintenance of the robotics solutions.

A summary of these rough estimations and their impact on the distribution of costs between the shares of the components of the Sample projects, presented below (Table 2).

Table 2. List of components of the Sample projects with the distribution of costs with integrated IT innovations. The parts of components, changed in relation to the respective values of Table 1 , presented in bold

\begin{tabular}{|c|c|c|c|c|c|}
\hline $\begin{array}{c}\text { Components } \\
\left(\boldsymbol{C}_{\text {Spc }}\right)\end{array}$ & $\begin{array}{c}\text { High-skilled la- } \\
\text { bour Avg.share of } \\
\text { cost with inte- } \\
\text { grated IT, \% }\end{array}$ & $\begin{array}{c}\text { Low-skilled labour } \\
\text { Avg.share of cost } \\
\text { with integrated IT, } \\
\%\end{array}$ & $\begin{array}{c}\text { Equipment } \\
\text { Avg.share of } \\
\text { cost with inte- } \\
\text { grated IT, \% }\end{array}$ & $\begin{array}{c}\text { Materials } \\
\text { Avg.share of } \\
\text { cost with inte- } \\
\text { grated IT, \% }\end{array}$ & $\begin{array}{c}\text { The extent of IT } \\
\text { innovations within } \\
\text { the components, } \%\end{array}$ \\
\hline Geodesy & 10 & - & 0 & - & 90 \\
\hline Geology & 10 & - & 0 & - & 90 \\
\hline Design & 52 & - & 0 & - & 48 \\
\hline Earthworks & 4 & 0 & 19 & 64 & 13 \\
\hline Road/Rail & 4 & 0 & 21 & 62 & 13 \\
\hline Structures & 4 & 0 & 12 & 73 & 14 \\
\hline Buildings & 3 & 0 & 10 & 84 & 7 \\
\hline $\begin{array}{c}\text { Noise and safety } \\
\text { barriers }\end{array}$ & 2 & 0 & & & \\
\hline
\end{tabular}

Lastly, for completion of the fourth task of the research, the calculated extent of IT innovations within the components, presented in Table 2, sums up to a rough 10\% benchmark for each Sample project cost: $10.46 \%$ of the Sample Road project cost, $10.55 \%$ of the Sample Rail project cost and $10.43 \%$ of the Sample Urban transport project cost. It should be noted that the vast majority of the changes, related to the integration of the IT innovations in the transportation construction sector, would directly affect the low-skilled and high-skilled labour market.

This means that a construction company, aiming to bid in a large EU transport project public procurement, potentially has an extent for substitution of its labour force with the IT-based solutions that amount to about $10 \%$ of the total planned project costs. On the other hand, the IT developers should be able to complete the sales of their innovations to the EU construction companies that operate in transport infrastructure construction sector, if they can offer a set of the IT-based solutions that perform the full scope of the following tasks and under the conditions listed below:

- Site surveys (geology, geodesy, etc.) including data compatibility with BIM-based 3D design programs;

$-3 \mathrm{D}$ construction design preparation and amendment activities;

- Simple and repetitive building and construction installation activities on construction sites; 
- The total costs of the full set of IT solutions should include:

- Development, repairs and maintenance costs during the construction period;

- Personnel instructions and training on system operation,

$-24 / 7$ helpdesk and customer support services.

- The total costs of the proposed set of IT technologies should not exceed $10 \%$ of the total planned project cost.

There are many reasons for the decision makers of construction companies in the EU to be attracted to IT solution integration proposals based on the previously described conditions.

Jarrahi's (2018) suggestion for effective complementarity scheme between humans and IT innovations would minimise the number of design errors and human-error caused accidents would be nearly eliminated with the BIM technology. Furthermore, the repetitive works would be eliminated, project implementation could speed up as the simple tasks, performed by robots would be implemented 24/7, construction companies could avoid social aspects of the employment issues, technology.

Finally, application of the full set of IT solutions, as listed above, thence would enable the construction companies to reduce their bid prices by at least the amount of the contingencies.

\section{Conclusions}

Analysis of information, gathered from various contemporary publications, has suggested major opportunities for integration of various IT innovations into the construction and development activities in general. It showed, however, practical obstacles that are preventing the EU transport infrastructure construction industry stakeholders to shift to ITbased operations for project implementation. In the environment of high-skilled labour shortages for operations of ITbased technologies as well as low-skilled labour shortages due to educational mismatches and behavioural issues, businesses are quite sceptical to proceed with IT-oriented transformations in their operational processes.

The reviewed literature, apart from various benefits of IT innovations, suggests financial considerations, unknown factors of performance, safety and social issues as the main obstacles, holding off the IT innovations from being applied to the transport projects.

Further application of the mathematical-statistical method of the data of completed transport projects, together with the application of it's results to the components of the Sample projects, provided an indication of the extent within the project scope for the application IT innovations.

This analysis shows that the extent for optimisation of a bill of quantities by blending in the IT technologies for a tender bid in a transport project is quite visible. It sums up to around $10 \%$ of total project cost and it is significant in the context of total project costs. The analysis consequently has proven the hypothesis. It is, moreover, mainly at the expense of the human labour demand.

Summary of the results of the research shows that the booming sector of the IT industry is bound to blend into the EU's transport projects, taking about $10 \%$ of each project scope. At first glance, shortages of low-skilled labour in the construction sector (as a whole) give an indication that the IT innovations would complement the existing low-skilled labour. This indication, however, appears to be quite threatening in the long run, because here the IT novelties are significantly more effective than humans in the performance of simple and repetitive tasks. Application of the IT novelties to the transport projects would quickly eliminate many unknown factors of their performance to the industry stakeholders and it would quickly create a situation of no return when the low-skilled jobs would be fully taken away from humans. It currently appears that the only two factors, keeping the IT innovations from taking over the low-skilled human work in transport projects, are high IT development costs and a shortage of high-skilled labour for management of IT innovations.

This research, consequently, gives a benchmark (10\% of a transport project cost) that should not be exceeded by IT developers if they want to be successful at selling their innovations to the transport infrastructure construction industry stakeholders. The innovations should perform the functions (and comply with the conditions), defined in the object analysis of this research.

The work, moreover, encourages the discussion on initiation of the initiatives at the political level aiming to the requalification of the existing unemployed labour force in order to meet the current labour demand in the construction market as a whole.

The article should largely contribute to the knowledge of research to seek effectiveness and attractiveness when developing IT innovations as it provides a purified vision of what customers in the transportation construction sector actually demands. The entrepreneurs, on the other hand, have clear indications of what particular IT innovations they could consider to acquire in order to optimise their project implementation.

This work is limited to the analysis of bills of quantities of the investment phase of transport infrastructure construction projects. For the search for more opportunities for effective application of IT innovations in the investment projects, further analyses should evaluate the comparative advantages of IT innovations in the maintenance phase of investment projects. These further analyses should be oriented to the needs of transport infrastructure owners that seek cost-effectiveness in their everyday infrastructure maintenance operations. The results of the further findings should provide a clear vision and direction for the researchers to seek innovation effectiveness in the development of future IT innovations. 


\section{References}

Acemoglu, D., \& Restrepo, P. (2017). Robots and jobs: Evidence from us labour markets (NBER Working Paper No 23285), 1-91. https://doi.org/10.3386/w23285

Alsop, R. (2008). The Trophy Kids Grow Up. How the Millennial Generation is Shaking up the Workplace. Retrieved from https://www.ebscohost.com/uploads/imported/thisTopic-dbTopic-1412.pdf

Ansip, A. (2017). Making the most of robotics and artificial intelligence in Europe. Retrieved from https://ec.europa.eu/commission/commissioners/2014-2019/ansip/blog/making-mostrobotics-and-artificial-intelligence-europe_en

Berman, B. (2012). 3-D printing: The new industrial revolution. Business Horizons, 55, $155-162$. https://doi.org/10.1016/j.bushor.2011.11.003

Boddington, P. (2017). Towards a Code of Ethics for Artificial Intelligence. Artificial Intelligence: Foundations, Theory, and Algorithms. Oxford University, United Kingdom: Springer. https://doi.org/10.1007/978-3-319-60648-4

Ciborowski, R. (2016). Innovation and competitive factors of non-R\&D industrial enterprises. The case of north-eastern Poland. International Journal of Transitions and Innovation Systems, 5(1), 66. https://doi.org/10.1504/IJTIS.2016.081565

Demian, P., \& Walters, D. (2014). The advantages of information management through building information modelling. Construction Management and Economics, 32, 1153-1165. https://doi.org/10.1080/01446193.2013.777754

Dimian, G. C., Aceleanu, M. I., Ileanu, B. V., \& Șerban, A. C. (2018). Unemployment and sectoral competitiveness in Southern European Union Countries. Facts and policy implications. Journal of Business Economics and Management, 19(3), 474-499. https://doi.org/10.3846/jbem.2018.6581

Dimitriou, L., Marinelli, M., \& Fragkakis, N. (2018). Early Bill-of-Quantities estimation of concrete road bridges: An Artificial intelligence-based application. Public Works Management \& Policy, 23(2), 127-149. https://doi.org/10.1177/1087724X17737321

Dziadosz, A., Tomczyk, A., \& Kapliński, O. (2015). Financial risk estimation in construction contracts. Procedia Engineering, 122, 120-128. https://doi.org/10.1016/j.proeng.2015.10.015

European Commission. (2014). Directorate-general for regional and urban policy. Guide to Cost-Benefit Analysis of Investment Projects. Economic appraisal tool for Cohesion Policy 2014-2020 (pp. 101-136). Retrieved from https://ec.europa.eu/inea/sites/inea/files/cba_guide_cohesion_policy.pdf

European Commission (2019). EU funding for TEN-T. Retrieved from https://ec.europa.eu/transport/themes/infrastructure/ten-tguidelines/project-funding_en

European Union. (2019). EU transport policy. Retrieved from https://europa.eu/european-union/topics/transport_en

Fenves, S. J. (1984). Artificial intelligence-based methods for infrastructure evaluation and repair. Department of Civil Engineering Carnegie-Mellon University. Pittsburgh. https://doi.org/10.1111/j.1749-6632.1984.tb27046.x

Holdren, J., \& Smith, M. (2016). Preparing for the future of artificial intelligence. Executive Office of the President National Science and Technology Council Committee on Technology. Retrieved from https://obamawhitehouse.archives.gov/sites/default/files/whitehouse_files/microsites/ostp/NSTC/preparing_for_the_future_of_ai.pdf

Jarrahi, M. H. (2018). Artificial intelligence and the future of work: Human-AI symbiosis in organizational decision making. Business Horizons, 61, 577-586. https://doi.org/10.1016/j.bushor.2018.03.007

Jones, K. (2018). 5 commercial construction trends to watch in 2018. Retrieved from https://www.constructconnect.com/blog/construction-news/5-commercial-construction-trendswatch-2018/

Kaplinski, O. (2018). Innovative Solutions in Construction Industry. Review of 2016-2018 Events and Trends. Engineering Structures and Technologies, 10(1), 27-33. Retrieved from https://journals.vgtu.lt/index.php/EST/article/view/1469

Karches, K. E. (2018). Against the iDoctor: why artificial intelligence should not replace physician judgment. Theoretical Medicine and Bioethics 39, 91-110. https://doi.org/10.1007/s11017-018-9442-3

Kohnová, L., Papula, J., \& Salajová, N. (2019). Internal factors supporting business and technological transformation in the context of Industry 4.0. Business: Theory and Practice, 20, 137-145. https://doi.org/10.3846/btp.2019.13

Li, R. Y. M., \& Ng, P. L. (2017). Wearable robotics and construction workers safety and health. In 8th International Conference on Applied Human Factors and Ergonomics, Los Angeles, CA.

Merriman, K. K. (2017). Valuation of human capital. Quantifying the Importance of an Assembled Workforce. University of Massachusetts Lowell, MA, United States: Springer. https://doi.org/10.1007/978-3-319-58934-3

Perkins, I., \& Skitmore, M. (2015). Three-dimensional printing in the construction industry: A review. International Journal of Construction Management, 15(1), 1-9. https://doi.org/10.1080/15623599.2015.1012136

Probst, L., Monfardini, E., Frideres, L., \& Cedola, D. (2014). Smart construction products and processes. In Business Innovation Observatory. European Union, PwC Luxembourg.

Raviv, G., Shapira, A., \& Barak, F. (2017). AHP-based analysis of the risk potential of safety indicators: a Case study of cranes in the construction industry. Safety Science, 91, 298-309. https://doi.org/10.1016/j.ssci.2016.08.027

Roszko-Wójtowicz, E., \& Białek, J. (2019). Measurement Of The Average Innovativeness Change Over Time In The Eu Member States. Journal of Business Economics and Management, 20(2), 268-293. https://doi.org/10.3846/jbem.2019.8337

Shehab, T. (2009). Automated measurement of earthwork volume in construction projects. Construction Innovation, 9, $341-358$. https://doi.org/10.1108/14714170910973538

Stamper, R. (1988). Pathologies of AI: Responsible use of artificial intelligence in professional work. AI \& Society, 2, 3-16. London: Springer. https://doi.org/10.1007/BF01891439 
State Council of the People's Republic of China. (2017). China issues a guideline on artificial intelligence development. Retrieved from http://english.gov.cn/policies/latest_releases/2017/07/20/content_281475742458322.htm

The Hong Kong Trade Development Council. (2019). Belt and Road. Retrieved from https://beltandroad.hktdc.com/en/insights/expert-insights-infrastructure-investment-trends-belt-and-road

Vysotskiy, A., Makarov, S., Zolotova, J., \& Tuchkevich, E. (2015). Features of BIM implementation using Autodesk software. Procedia Engineering, 117, 1143-1152. https://doi.org/10.1016/j.proeng.2015.08.248

Wladawsky-Berger, I. (2017). The emerging, unpredictable age of AI. MIT. Retrieved from http://ide.mit.edu/newsblog/blog/emerging-unpredictable-age-ai

Yi, R., \& Li, M. (2018). An Economic Analysis on Automated Construction Safety. Internet of Things, Artificial Intelligence and $3 D$ Printing. Hong Kong Shue Yan University, Hong Kong: Springer

Zhang, S., Lee, J. K., Venugopal, M., Teizer, J., \& Eastman, C. (2013). Integrating BIM and safety: An automated rule-based checking system for safety planning and simulation. Retrieved from http://www.irbnet.de/daten/iconda/CIB_DC24442.pdf

Zhu, X., Song, B., Ni, Y., Ren, Y., \& Li, R. (2016). Business trends in the digital era. evolution of theories and applications. China Europe International Business School, Shanghai, China: Springer. 